\title{
A randomized, double-blind, crossover comparison of the efficacy and safety of oral controlled-release tramadol and placebo in patients with painful osteoarthritis
}

\author{
Carter Thorne $\mathrm{MD}^{1}$, André D Beaulieu MD², Denis J Callaghan $\mathrm{MD}^{3}$, William F O'Mahony MD ${ }^{4}$, \\ John M Bartlett $M D^{5}$, Richard Knight $M D^{6}$, Gunnar R Kraag MD , Ronald Akhras $\mathrm{MD}^{8}$, Paula S Piraino PhD ${ }^{9}$, \\ John Eisenhoffer $\mathrm{MD}^{9}$, Zoltan Harsanyi $\mathrm{MBA}^{9}$, Andrew C Darke $\mathrm{PhD}^{9}$
}

\begin{abstract}
C Thorne, AD Beaulieu, DJ Callaghan, et al. A randomized, double-blind, crossover comparison of the efficacy and safety of oral controlled-release tramadol and placebo in patients with painful osteoarthritis. Pain Res Manage 2008;13(2):93-102.
\end{abstract}

OBJECTIVE: To compare the efficacy and safety of controlledrelease (CR) tramadol (Zytram XL, Purdue Pharma, Canada) and placebo in patients with painful osteoarthritis.

METHODS: Patients underwent analgesic washout for two to seven days before random assignment to $150 \mathrm{mg}$ daily of CR tramadol or placebo, and were titrated weekly to $200 \mathrm{mg}, 300 \mathrm{mg}$ or a maximum of $400 \mathrm{mg}$ once daily. After four weeks, patients crossed over to the alternate treatment for another four weeks. Plain acetaminophen was provided as a rescue analgesic. All patients who completed the crossover study were eligible to receive open label CR tramadol for six months.

RESULTS: Seventy-seven of 100 randomly assigned patients were evaluable for efficacy. CR tramadol resulted in significantly lower visual analogue scale pain intensity scores $(37.4 \pm 23.9$ versus 45.1 $\pm 24.3, P=0.0009)$. Western Ontario and McMaster Universities osteoarthritis index subscale scores for pain $(189.0 \pm 105.0$ versus $230.0 \pm 115.4 ; \mathrm{P}=0.0001)$ and physical function $(632.4 \pm 361.3$ versus $727.4 \pm 383.4 ; \mathrm{P}=0.0205)$ were significantly better with $\mathrm{CR}$ tramadol. Total pain and disability $(22.8 \pm 14.5$ versus $27.2 \pm 14.8 ; \mathrm{P}=0.0004)$, and overall pain and sleep $(104.7 \pm 98.0$ versus $141.0 \pm 108.2$; $\mathrm{P}=0.0005$ ) scores in the Pain and Sleep Questionnaire were significantly lower for CR tramadol. Short-form 36 Health Survey scores were significantly better during $\mathrm{CR}$ tramadol treatment for the pain index $(38.8 \pm 10.8$ versus $35.6 \pm 9.0 ; \mathrm{P}=0.0100)$, general health perception $(46.5 \pm 11.2$ versus $44.4 \pm 11.6 ; \mathrm{P}=0.0262)$, vitality $(43.1 \pm 13.2$ versus $40.2 \pm 13.7 ; \mathrm{P}=0.0255)$ and overall physical components $(40.8 \pm 8.9$ versus $37.8 \pm 7.7 ; \mathrm{P}=0.0002)$. CR tramadol treatment was preferred by $55.8 \%$ of patients $(\mathrm{P}=0.0005)$ versus $20.8 \%$ and $23.4 \%$ of patients who chose placebo or had no preference, respectively. These improvements were sustained for up to six months, and $86.5 \%$ of patients reported at least moderate benefit from CR tramadol during long-term treatment.

CONCLUSION: CR tramadol is effective for the management of painful osteoarthritis.

Key Words: Chronic pain; Controlled-release; Osteoarthritis; Tramadol
Une comparaison croisée aléatoire et à double insu de l'efficacité et de l'innocuité du tramadol à libération contrôlée par voie orale et d'un placebo chez des patients souffrant d'arthrose douloureuse

OBJECTIF : Comparer l'efficacité et l'innocuité du tramadol à libération contrôlée (TLC) (Zytram XL, Purdue Pharma, Canada) et d'un placebo chez des patients souffrant d'arthrose douloureuse.

MÉTHODOLOGIE : Les patients ont subi un sevrage de leurs analgésiques pendant deux à sept jours avant d'être répartis de manière aléatoire entre un traitement de $150 \mathrm{mg}$ de TLC et un placebo, et ils ont été titrés toutes les semaines à $200 \mathrm{mg}, 300 \mathrm{mg}$ ou un maximum de $400 \mathrm{mg}$ une fois par jour. Au bout de quatre semaines, les patients sont passés à l'autre traitement, de nouveau pendant quatre semaines. Le simple acétaminophène servait d'analgésique de rattrapage. Tous les patients qui terminaient l'étude croisée étaient admissibles à recevoir un traitement ouvert au TLC pendant six mois.

RÉSULTATS : Soixante-dix-sept des 100 patients divisés au hasard pouvaient faire l'objet d'une évaluation d'efficacité. Selon l'échelle visuelle analogique, le TLC s'associait à une diminution considérable de l'intensité de la douleur $(37,4 \pm 23,9$ par rapport à $45,1 \pm 24,3, \mathrm{P}=0,0009)$. Les indices des sous-échelles de la douleur de l'université de Western Ontario et de l'université McMaster (189,0 $\pm 105,0$ par rapport à 230,0 $\pm 115,4$, $\mathrm{P}=0,0001)$ et la fonction physique $(632,4,0 \pm 361,3$ par rapport à $727,4 \pm 383,4, \mathrm{P}=0,0205)$ s'amélioraient de manière significative avec le TLC. Les indices de douleur totale et d'incapacité $(22,8 \pm 14,5$ par rapport à $27,2 \pm 14,8, \mathrm{P}=0,0004)$ et de douleur globale et de sommeil $(104,7 \pm 98,0$ par rapport à $141,0 \pm 108,2, \mathrm{P}=0,0005)$ du questionnaire sur la douleur et le sommeil étaient beaucoup plus faibles pour le TLC. Les indices du questionnaire court en 36 questions étaient beaucoup plus positifs pendant le traitement au TLC pour ce qui est de l'indice de la douleur $(38,8 \pm 10,8$ par rapport à $35,6 \pm 9,0, \mathrm{P}=0,0100)$, de la perception de santé générale $(46,5 \pm 11,2$ par rapport à $44,4 \pm 11,6, P=0,0262)$, de la vitalité $(43,1 \pm 13,2$ par rapport à 40,2 $\pm 13,7, \mathrm{P}=0,0255)$ et des éléments physiques globaux $(40,8 \pm 8,9$ par rapport à $37,8 \pm 7,7, \mathrm{P}=0,0002)$. Le traitement au TLC était préféré par $55,8 \%$ des patients $(\mathrm{P}=0,0005)$ par rapport à $20,8 \%$ et $23,4 \%$ de ceux qui prenaient un placebo ou qui n'avaient pas de préférence, respectivement. Ces améliorations étaient maintenues jusqu'à six mois, et $86,5 \%$ des patients déclaraient au moins des bienfaits modérés du TLC pendant le traitement prolongé.

CONCLUSION : Le TLC est efficace pour la prise en charge de l'arthrose douloureuse.

${ }^{1}$ The Arthritis Program Research Group Inc, Newmarket, Ontario; ${ }^{2}$ Centre de Rhumatologie St-Louis, Ste Foy, Quebec; ${ }^{3}$ Hamilton, Ontario; ${ }^{4}$ Corunna Medical Research Centre, Corunna, Ontario; ${ }^{5}$ London Road Diagnostic and Medical Centre, Sarnia, Ontario; ${ }^{6}$ Ultra-Med Inc, Pointe-Claire, Quebec; ${ }^{7}$ The Ottawa Hospital, Ottawa, Ontario; ${ }^{8}$ Centre Medicale Acadie, Montreal, Quebec; ${ }^{9}$ Purdue Pharma, Pickering, Ontario

Correspondence: Dr John Eisenhoffer, Purdue Pharma, 575 Granite Court, Pickering, Ontario L1W 3W8. Telephone 800-387-5349, fax905-420-2503, e-mail john.eisenhoffer@purdue.ca 
A n estimated three million people (approximately 10\%) in Canada have signs and symptoms of osteoarthritis (OA), making it one of the most important public health issues among the musculoskeletal disorders (1). In the United States, more than $13 \%$ of people aged 55 to 64 years of age have pain and functional limitation due to knee OA. In the 65- to 74-yearold age range, the numbers rise to more than $17 \%$ (2). Pathological changes result in various symptoms, including stiffness, swelling, decreased mobility, instability, deformity and several different types of joint pain. Current management of $\mathrm{OA}$ is symptomatic and directed primarily toward reducing inflammation, relieving pain, optimizing joint function and minimizing disability (3). A survey of Ontario patients with disabling knee and/or hip OA found estimated direct and indirect arthritis-attributable costs of $\$ 12,200$ per person annually, mostly due to time lost from employment or leisure (4).

Conventional pharmacological management options for OA pain primarily include nonsteroidal anti-inflammatory drugs (NSAIDs) and acetaminophen. Although NSAIDs effectively reduce mild to moderate pain, they can be suboptimal for the treatment of moderate to severe pain (5). Longterm use of NSAIDs may lead to gastrointestinal complications such as ulceration and bleeding $(6,7)$ and, in patients with a history of or increased risk for cardiovascular disease, the use of cyclo-oxygenase 2 selective inhibitors are associated with an increased risk for cardiovascular events (8-10). The American Heart Association recently released a statement recommending that NSAIDs be used only after other treatments for musculoskeletal pain have failed, rather than as a first-line option (11).

Combination opioid and acetaminophen products have traditionally been used for the treatment of moderate to severe OA pain. However, several studies have shown that patients with chronic noncancer pain can experience sustained analgesia with opioid therapy without developing addiction (12-15). As a result, opioids such as tramadol are receiving greater consideration for the treatment of this type of pain.

Tramadol is a centrally acting aminocyclohexanol analgesic with complementary mechanisms, including activation of $\mu$-opioid receptors, and inhibition of norepinephrine and serotonin reuptake (16). The development of tolerance has been reported to be rare $(17,18)$ and withdrawal symptoms, when present, are considered relatively mild (18). There has been little evidence of abuse in foreign postmarketing experience $(19,20)$ and the overwhelming majority of cases occur in individuals with a history of substance abuse (19). Recently, the World Health Organization Expert Committee on Drug Dependence determined that, despite an increase in the extent of its therapeutic use, tramadol continues to be minimally abused, and opted to forgo a formal review of its present status as a nonscheduled substance (21). Compared with other centrally acting analgesics, tramadol lacks typical adverse effects, producing only mild respiratory depression (22), no clinically relevant cardiovascular effects (23), and minor effects on bowel function and colonic transit time $(24,25)$. Therefore, tramadol may be potentially useful for the treatment of OA pain.

Tramadol is generally well-tolerated and has been evaluated for the treatment of acute pain (26), chronic pain (27), cancer pain $(28,29)$, painful diabetic neuropathy $(30,31)$, polyneuropathy (32), fibromyalgia (33) and OA pain (34-41). The American Pain Society recommends tramadol for the management of OA pain when NSAIDs alone produce inadequate pain relief (42). Tramadol has also been shown to be effective in the treatment of chronic pain in combination with acetaminophen (43-48). Single-entity, controlled-release (CR) opioid formulations provide the advantage of aroundthe-clock dosing, without the restriction that arises from the acetaminophen component of combination preparations when titrating the dose to optimal effect (14).

The short elimination half-life of immediate-release (IR) tramadol necessitates dosing every $4 \mathrm{~h}$ to $6 \mathrm{~h}$ to maintain optimal levels of analgesia in chronic pain. To overcome the difficulties associated with treatment dosing, Purdue Pharma formulated once-a-day CR tramadol tablets (Zytram XL, Purdue Pharma, Canada). CR preparations provide an extended duration of action, more constant plasma concentrations, a reduced dosing frequency, and the potential for improved compliance and therapeutic outcomes. The bioavailability of this new once-daily CR tramadol formulation is comparable with IR formulations, with a half-life three to four times longer ( $16 \mathrm{~h}$ versus $4 \mathrm{~h}$ to $6 \mathrm{~h}$ ) and an extent of absorption similar to IR tramadol given three times daily (49). In a previous study (50) of this formulation for the treatment of chronic noncancer pain, including $\mathrm{OA}$, patients who received scheduled, once daily CR tramadol took higher daily doses and had better pain control than patients taking IR tramadol as needed. In addition, the study demonstrated that CR tramadol provided a full $24 \mathrm{~h}$ of pain relief without any evidence of endof-dosing-period analgesic failure.

The objective of the present randomized, double-blind, crossover study was to compare CR tramadol with placebo in the treatment of moderate or greater OA pain of the hip(s) and/or knee(s). A six-month open label extension phase served to evaluate the long-term efficacy and safety of CR tramadol, and to confirm the sustainability of the benefits provided during the double-blind phase.

\section{Patients}

\section{METHODS}

Men and nonpregnant, non-nursing women over the age of 18 years, diagnosed with $\mathrm{OA}$ and requiring the use of acetaminophen, anti-inflammatory agents or combination opioid and nonopioid analgesics for at least three months were eligible for the present study. OA was defined by the presence of hip and/or knee symptoms (pain, stiffness, disability) and signs (bony crepitus), as well as radiographic evidence of OA in the medial and/or lateral tibiofemoral compartment (with or without patellofemoral OA), or in the hip. Radiographic evidence was defined by the presence of at least one of the following: osteophytes, joint space narrowing, periarticular sclerosis or subchondral cysts, with a minimum grade 2 severity, as illustrated in the Atlas of Standard Radiographs of Arthritis (51). Patients with more advanced grades were eligible if they were not awaiting surgery. Patients using only acetaminophen at the time of enrollment were required to have pain of at least moderate intensity (a 2 or greater on a 0 to 4 ordinal pain scale) at both visits 1 and 2. Patients treated with any other opioid or nonopioid analgesic were required to have at least moderate pain (a 2 or greater on a 0 to 4 ordinal pain scale) after a two to seven day washout period at visit 2 .

Patients with intolerance to any opioid, tramadol or acetaminophen were excluded. Patients who required more than eight tablets per day of acetaminophen plus codeine, or its 
analgesic equivalent, or with a history of drug or alcohol abuse were also excluded. The following medical conditions were exclusionary: any other form of joint disease or previous replacement of the study joint, renal or hepatic impairment (alanine aminotransferase or aspartate aminotransferase more than two times the upper limit of the normal range), shortened gastrointestinal transit time, peptic ulcer disease, inflammatory disease of the gastrointestinal tract, cardiac or respiratory conditions that put the patient at risk for respiratory depression, a history of seizures or a recognized risk for seizure, and any other condition that would adversely affect the patient's safety or obscure the assessment of efficacy. Patients receiving monoamine oxidase inhibitors, carbamazepine, quinidine, selective serotonin reuptake inhibitors or tricyclic antidepressants, cyclobenzaprine, promethazine, neuroleptics, warfarin or digoxin were excluded. Patients who received an investigational drug within the last month were also ineligible. Research ethics boards (both local and central) approved the protocol and informed consent, and each patient gave written informed consent before participating in the present study.

\section{Medications}

Medications included oral CR tramadol $150 \mathrm{mg}, 200 \mathrm{mg}$, $300 \mathrm{mg}$ and $400 \mathrm{mg}$ tablets and matching placebo tablets. All patients were randomly assigned to receive either active or placebo CR tramadol $150 \mathrm{mg}$ once daily in the morning. Both the active and placebo doses were titrated to $200 \mathrm{mg}, 300 \mathrm{mg}$ or $400 \mathrm{mg}$ weekly, based on pain control and side effects. Patients who were unable or unlikely to tolerate a dose increase were maintained on their previous maximum tolerated dose until the next clinic visit, at which time the acceptability of a dose increase was re-evaluated. Breakthrough pain was managed throughout the study with $325 \mathrm{mg}$ to $650 \mathrm{mg}$ plain acetaminophen (Tylenol, McNeil Consumer Healthcare, Canada) every $4 \mathrm{~h}$ to $6 \mathrm{~h}$ as required.

\section{Study design}

The present study was a randomized, double-blind, eight-week crossover comparison of CR tramadol, administered once per day in the morning, at a dose of $150 \mathrm{mg}, 200 \mathrm{mg}, 300 \mathrm{mg}$ or $400 \mathrm{mg}$, and placebo. Ethics approval was obtained from Institutional Review Board Services (Aurora, Ontario), the University of Saskatchewan Biomedical Research Ethics Board (Saskatoon, Saskatchewan) and the Ottawa Hospital Research Ethics Board (Ottawa, Ontario). Patients were withdrawn from all analgesics (except acetaminophen) for a two- to seven-day washout period before random assignment. Patients returned to the clinic for weekly visits, and underwent four weeks of treatment in the first phase of the study, before switching to the alternate treatment for another four weeks. Patients who successfully completed the randomized phase were eligible to receive open label CR tramadol for a period of up to six months.

Throughout the washout period and the randomized treatment phase, patients recorded their pain intensity in a diary, twice per day (08:00 and 20:00), using a five-point ordinal scale $(0=$ none, $1=$ mild, $2=$ moderate, $3=$ severe, $4=$ excruciating) and a $100 \mathrm{~mm}$ visual analogue scale (VAS). The VAS was a $100 \mathrm{~mm}$ unmarked line, bounded on the left by 'no pain' and on the right by 'excruciating pain'. Pain intensity over the previous $24 \mathrm{~h}$ and over the previous week was also assessed at two, four and six months during the open label phase, using the $100 \mathrm{~mm}$ VAS and five-point ordinal scales.
At baseline, crossover, the end of the double-blind study, and every two months during the open label phase, patients completed the pain, stiffness and physical function subscales of The Western Ontario and McMaster Universities (WOMAC) OA index (52). Each subscale rating is determined by adding a series of $100 \mathrm{~mm}$ VAS scales. The pain subscale consists of five items: 'pain walking on a flat surface', 'pain going up or down stairs', 'pain at night while in bed', 'pain sitting or lying' and 'pain standing upright' (anchors: no pain, extreme pain). The stiffness subscale consists of two items: 'how severe is stiffness on awakening' and 'how severe is stiffness later in the day' (anchors: no stiffness, extreme stiffness). The physical function subscale consists of 17 items: 'difficulty descending stairs', 'difficulty ascending stairs', 'difficulty rising from sitting', 'difficulty standing', 'difficulty bending to the floor', 'difficulty walking on flat surfaces', 'difficulty getting in/out of a car', 'difficulty going shopping', 'difficulty putting on socks/stockings', 'difficulty rising from bed', 'difficulty taking off socks/stockings', 'difficulty lying in bed', 'difficulty getting in/out of bath', 'difficulty sitting', 'difficulty getting on/off toilet', 'difficulty with heavy domestic duties' and 'difficulty with light domestic duties' (anchors: no difficulty, extreme difficulty).

Patients rated their pain-related disability at baseline, crossover, end of study, and every two months throughout the open label phase using the Pain and Disability Index (PDI) $(53,54)$, which consists of seven 11-point ordinal subscales: family/home responsibilities, recreation, social activity, occupation, sexual behaviour, self care and life support activity (anchors: no disability, total disability). An overall disability score was determined by adding the individual ratings $(12,15,50,55,56)$.

At baseline, crossover and the end of the study, as well as at two, four and six months into the open label extension, the impact of pain on sleep (since the last evaluation) was assessed with the eight-item Pain and Sleep Questionnaire $(15,16,50,55,56)$. Seven items were rated on a $100 \mathrm{~mm}$ VAS (anchors: never to always), and the final item was based on the number of hours of sleep. Items 1 through 5 ('trouble falling asleep', 'needed pain medication to sleep', 'needed sleep medication to sleep', 'awakened by pain at night', 'awakened by pain in the morning') were added to determine a composite score $(56,57)$.

At baseline, crossover, end of study visits and every two months throughout the open label phase, the general health status outcome measure - the Short-form 36 Health Survey (SF-36) - was administered (58). The SF-36 includes one multi-item scale measuring eight health concepts: physical functioning, role limitations due to physical health problems, bodily pain, general health, vitality (energy/fatigue), social functioning, role limitations due to emotional problems, and mental health (psychological distress and psychological wellbeing).

Effectiveness of treatment was assessed by the patient and the investigator at screening, baseline, crossover and end of the double-blind study using a four-point categorical scale (not effective, slightly effective, moderately effective, highly effective) $(55,56,59)$. Overall treatment phase preference was assessed by the patient and the investigator at the end of the study, without unblinding the treatment allocation, by answering the question: "Which treatment period did you prefer in the management of your pain?" (treatment period 1; treatment period 2; no preference). 


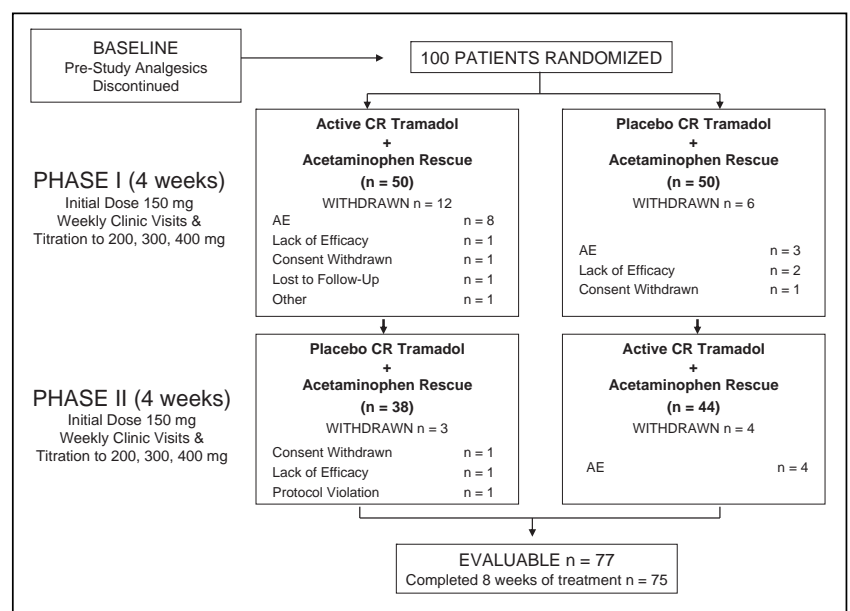

Figure 1) Study design and patient disposition. AE Adverse events; CR Controlled-release

During the open label phase, patients rated the overall clinical benefit conferred by CR tramadol at all scheduled and unscheduled clinic visits using a four-point scale $(1=$ a great deal of benefit; 2 = moderate benefit; 3 = slight benefit; $4=$ no benefit).

Adverse events spontaneously reported by patients and observed by the investigator were recorded at each clinic visit throughout the double-blind and the open label phases.

\section{Data analysis}

The primary measures of efficacy were the VAS and five-point ordinal pain intensity scales from the patient daily diaries averaged over the last week of treatment in each phase. It was estimated that with 60 patients completing the study, there would be $80 \%$ power $(\beta=0.20)$ at the $5 \%$ significance level $(\alpha=0.05)$ to detect a difference of $10 \mathrm{~mm}$ in VAS pain intensity. Analysis of efficacy was restricted to patients who completed at least two weeks of treatment in each study phase (per protocol population), while all patients who received test medication were evaluated for safety. The full analysis set (intent-to-treat [ITT]) was used to confirm the results of the primary efficacy variables, the WOMAC and overall treatment preference.

Three-way ANOVA was used to test for the effect of treatment, phase and sequence (carryover) using the mean scores by treatment. The patient-within-sequence variance was used as the error term for testing sequence effect.

Secondary end points included: the WOMAC OA index, PDI, Pain and Sleep Questionnaire, SF-36, treatment effectiveness and treatment preference. The use of rescue medication was compared for each treatment, based on the average daily consumption, and was summarized each week. All secondary assessments were analyzed using a three-way ANOVA to test for the effects of treatment, phase and sequence (carryover). Comparison of treatment preference rates was tested using Prescott's test (60), which accounts for responses of 'no preference'.

The change from baseline (CFB) in the double-blind phase was calculated for each treatment for both the primary and secondary end points. During the open label phase, the CFB was calculated, where baseline was the last week of treatment during the double-blind phase. In both cases, the paired $t$ test was used to test the null hypothesis of no CFB.
Adverse events were coded using preferred terms (Coding Symbols for a Thesaurus of Adverse Reaction Terms, Fourth Edition [61]). McNemar's test was applied to detect differences in the overall frequency of side effects between the treatments.

All data are reported as mean \pm SD. Statistical significance was defined as $\mathrm{P}<0.05$ for a two-tailed hypothesis.

\section{Patient disposition}

\section{RESULTS}

There were 100 randomly assigned patients (45 men, 55 women, mean age $61.0 \pm 10.3$ years). Eighty-two per cent of patients had OA of the knee, 9\% had OA of the hip and 9\% had $\mathrm{OA}$ in both locations. The mean duration of OA pain was $8.3 \pm 6.8$ years. Patients assessed as having an OA grade of 2 or 3 on their study joint made up $94.5 \%$ of randomly assigned patients. Twenty-five patients withdrew after random assignment (15 due to adverse events, four due to lack of efficacy, three due to withdrawn consent, one due to a protocol violation, one was lost to follow-up and one left early because of plans to leave town). Of the 15 patients who withdrew due to adverse events, 12 were receiving CR tramadol and three were receiving placebo at the time of their withdrawal. Seventyseven patients (36 men, 41 women) were evaluable for efficacy (Figure 1), with an average age of $59.4 \pm 9.6$ years and a mean weight and height of $91.0 \pm 21.4 \mathrm{~kg}$ and $167 \pm 10.9 \mathrm{~cm}$, respectively.

\section{Medication dose}

The mean daily dose of study medication during the last week of treatment of each phase was significantly lower in the active CR tramadol group $(340.3 \pm 90.7 \mathrm{mg} /$ day $)$ than in the placebo group $(372.1 \pm 57.6 \mathrm{mg} /$ day; $\mathrm{P}=0.0100)$. There was a significantly greater use of rescue medication during the placebo phase (3.4 \pm 3.6 tablets/day) than during the $\mathrm{CR}$ tramadol phase (2.4 \pm 3.1 tablets/day; $\mathrm{P}=0.0071)$.

\section{Pain intensity}

At baseline, the daily diary pain intensity scores were $50.8 \pm 17.3 \mathrm{~mm}$ for the VAS scale and $2.2 \pm 0.5$ for the five-point ordinal scale. During the last week of treatment, the mean VAS score was significantly lower in the CR tramadol group $(37.4 \pm 23.9 \mathrm{~mm})$ than in the placebo group $(45.1 \pm 24.3 \mathrm{~mm}$; $\mathrm{P}=0.0009)$. The CFB in the VAS score was $26.5 \%(\mathrm{P}=0.0001)$ for $\mathrm{CR}$ tramadol treatment and $11.3 \%(\mathrm{P}=0.0244)$ for placebo treatment (Figure 2). The five-point ordinal scores with CR tramadol were also significantly lower than placebo scores during the last week of treatment $(1.7 \pm 0.8$ versus $1.9 \pm 0.8 ; \mathrm{P}=0.0060)$. The CFB for the ordinal pain scores was $24.3 \%(\mathrm{P}=0.0001)$ for CR tramadol and $13.4 \%(P=0.0003)$ for placebo treatment. The ITT analysis confirmed these results, with CR tramadol scores significantly lower than placebo for both VAS $(38.2 \pm 22.7 \mathrm{~mm}$ versus $47.7 \pm 25.7 \mathrm{~mm}, \mathrm{P}=0.0001$ ) and the ordinal pain intensity scale $(1.7 \pm 0.8$ versus $2.0 \pm 0.9, P=0.0010)$. An analysis of carryover effect found no significance.

\section{WOMAC OA index}

The composite scores for the pain and physical function inventories of the WOMAC OA index during the last week of each treatment phase were significantly better following CR tramadol treatment, compared with placebo treatment. The composite scores for the pain inventory were $189.0 \pm 105.0 \mathrm{~mm}(34.5 \% \mathrm{CFB}, \mathrm{P}=0.0001)$ for $\mathrm{CR}$ tramadol 


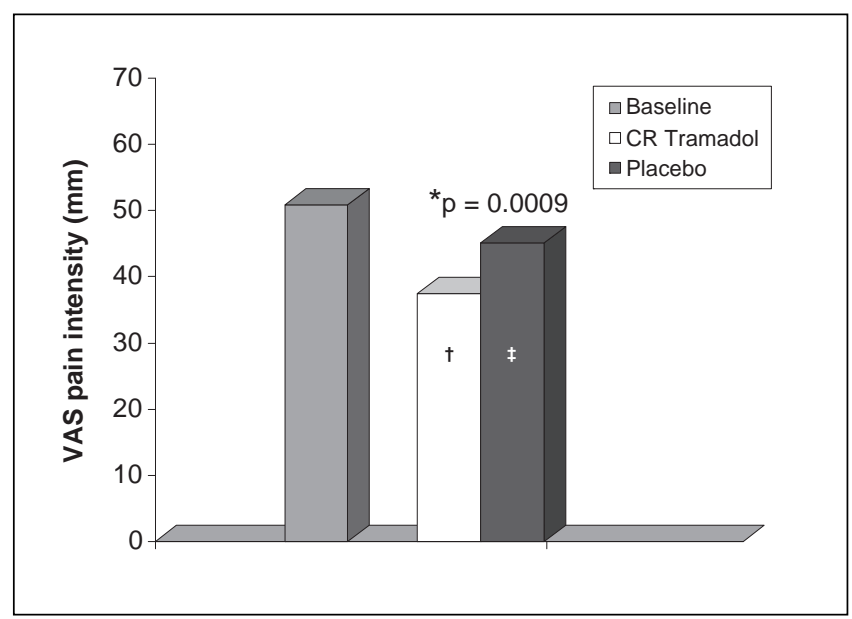

Figure 2) Mean visual analogue score (VAS) pain intensities for the last week of treatment (diary scores). $* P=0.0009$ between treatments; ${ }^{\dagger} \mathrm{P}=0.0001 ; \vdots \mathrm{P}=0.0244$ decrease from baseline. CR Controlledrelease

treatment and $230.0 \pm 115.4 \mathrm{~mm}(19.8 \% \mathrm{CFB}, \mathrm{P}=0.0001)$ for placebo treatment $(\mathrm{P}=0.0007)$. For the physical function subscale, the composite scores were $632.4 \pm 361.3 \mathrm{~mm}(29.4 \%$

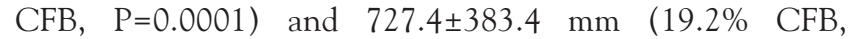
$\mathrm{P}=0.0001)$ following $\mathrm{CR}$ tramadol and placebo treatment, respectively $(\mathrm{P}=0.0205)$. The composite scores for the stiffness subscale were not significantly different between the treatment groups, although there were significant changes from baseline following both CR tramadol (23.4\% CFB, P=0.0001) and placebo treatment (19.5\% CFB, $\mathrm{P}=0.0001)$ (Figure 3). These results were confirmed by the ITT analysis (pain subscale: CR tramadol, $196.1 \pm 103.6 \mathrm{~mm}$ versus placebo, $244.4 \pm 124.8 \mathrm{~mm}$, $\mathrm{P}=0.0001$; physical function subscale: CR tramadol, $656.1 \pm 353.4 \mathrm{~mm}$ versus placebo, $773.1 \pm 404.2 \mathrm{~mm}, \mathrm{P}=0.0037$ ).

\section{PDI}

On the PDI, a higher score is indicative of greater disability. Six of the seven subscales were significantly lower in the final week of treatment with CR tramadol than with placebo (all except 'sexual behaviour'). The total pain and disability score was also significantly better following CR tramadol treatment $(22.8 \pm 14.5)$ than following placebo treatment $(27.2 \pm 14.8$; $\mathrm{P}=0.0004$ ) (Table 1). Five of the seven subscales, as well as the total pain and disability score, showed significant improvements from baseline after treatment with CR tramadol (CFB range $19.7 \%$ to $34.7 \%, \mathrm{P} \leq 0.0099)$. None of the subscales, nor the overall pain and disability score, showed significant differences from baseline with placebo treatment $(<8.3 \%$, $\mathrm{P} \geq 0.1962$ ) (Table 1).

\section{Pain and Sleep Questionnaire}

There were significantly better scores on the Pain and Sleep Questionnaire during the last week of treatment for the CR tramadol group, compared with the placebo group, in five of eight items on the questionnaire ('trouble falling asleep', 'needed pain medication to sleep', 'needed sleep medication to sleep', 'awakened by pain in the morning', 'average hours of sleep per night'). The overall pain and sleep score was also significantly better for CR tramadol than for placebo (104.7 $\pm 98.0 \mathrm{~mm}$ versus $141.0 \pm 108.2 \mathrm{~mm} ; \mathrm{P}=0.0008)$ (Table 2). In addition, significant changes from baseline were observed in

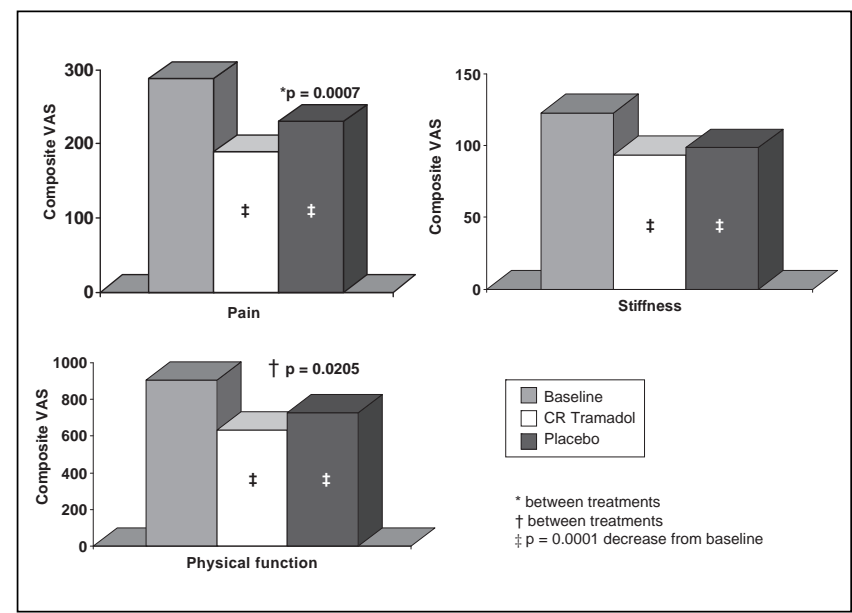

Figure 3) Western Ontario and McMaster Universities osteoarthritis index during the last week of treatment. ${ }^{*} P=0.0007$ between treatments; ${ }^{\dagger} \mathrm{P}=0.0205$ between treatments; ${ }^{\ddagger} \mathrm{P}=0.0001$ decrease from baseline. CR Controlled-release; VAS Visual analogue scores

\section{TABLE 1}

Pain and Disability Index during the last week of treatment

\begin{tabular}{|c|c|c|c|c|}
\hline & Baseline & $\begin{array}{l}\text { Controlled- } \\
\text { release } \\
\text { tramadol }\end{array}$ & Placebo & $\mathbf{P}^{*}$ \\
\hline $\begin{array}{l}\text { Family and home } \\
\text { responsibilities }\end{array}$ & $4.7 \pm 2.6$ & $3.5 \pm 2.4^{\dagger}$ & $4.4 \pm 2.4$ & 0.0001 \\
\hline Recreation & $6.1 \pm 2.8$ & $4.8 \pm 2.8^{\dagger}$ & $5.6 \pm 2.7$ & 0.0083 \\
\hline Social activity & $4.1 \pm 2.7$ & $3.2 \pm 2.5^{\dagger}$ & $4.1 \pm 2.7$ & 0.0028 \\
\hline Occupation & $5.0 \pm 2.8$ & $3.9 \pm 2.7^{\dagger}$ & $4.6 \pm 2.8$ & 0.0047 \\
\hline Sexual behaviour & $3.5 \pm 2.9$ & $3.6 \pm 3.0$ & $3.6 \pm 2.0$ & 0.8396 \\
\hline Self care & $2.7 \pm 2.4$ & $2.3 \pm 2.3$ & $2.9 \pm 2.5$ & 0.0089 \\
\hline Life support & $2.3 \pm 2.4$ & $1.5 \pm 2.1^{\dagger}$ & $2.1 \pm 2.4$ & 0.0499 \\
\hline $\begin{array}{l}\text { Total pain } \\
\text { and disability }\end{array}$ & $28.5 \pm 14.0$ & $22.8 \pm 14.5^{\dagger}$ & $27.2 \pm 14.8$ & 0.0004 \\
\hline
\end{tabular}

Results presented as mean $\pm S D$. *Between treatments; ${ }^{\dagger}$ Change from baseline $P \leq 0.0099$

all eight of the items following treatment with CR tramadol (CFB range: $8.0 \%$ to $51.3 \%, \mathrm{P} \leq 0.0030$ ), but only in four categories after placebo (CFB range: $2.4 \%$ to $26.4 \%, \mathrm{P} \leq 0.0030$ ). The overall pain and sleep score was significantly improved from baseline for both treatments (CR tramadol $42.9 \%$, $\mathrm{P}=0.0001$; placebo $21.8 \%, \mathrm{P}=0.0023$ ) (Table 2).

\section{SF-36}

Scores for the Canadian normalized domains of the SF-36 at the end of the treatment period were significantly better following CR tramadol compared with placebo treatment in three of eight categories: 'pain index' $(38.81 \pm 10.76$ versus 35.61 $\pm 9.01, \quad \mathrm{P}=0.0100)$; 'general health perception' $(46.54 \pm 11.20$ versus $44.39 \pm 11.63, \mathrm{P}=0.0262)$; and 'vitality' $(43.14 \pm 13.20$ versus $40.21 \pm 13.70, \mathrm{P}=0.0255)$. The overall physical component score also significantly improved following treatment with CR tramadol (40.78 \pm 8.68$)$ compared with placebo $(37.78 \pm 7.71, \mathrm{P}=0.0002)$. In all other categories, there were no significant differences found between the treatment groups ( $\mathrm{P}>0.0693$ ) (Figure 4).

There were significant improvements over baseline in seven of the eight functional categories of the SF-36 following CR tramadol treatment (CFB range $4.5 \%$ to $18.3 \%$, 
TABLE 2

Pain and Sleep Questionnaire during the last week of treatment

\begin{tabular}{|c|c|c|c|c|}
\hline & Baseline & $\begin{array}{c}\text { Controlled- } \\
\text { release } \\
\text { tramadol }\end{array}$ & Placebo & $\mathbf{P}^{*}$ \\
\hline $\begin{array}{l}\text { Trouble falling } \\
\text { asleep }\end{array}$ & $41.0 \pm 26.7$ & $24.2 \pm 21.6^{\dagger}$ & $31.6 \pm 24.9^{\ddagger}$ & 0.0067 \\
\hline $\begin{array}{l}\text { Needed pain } \\
\text { medication to sleep }\end{array}$ & $33.0 \pm 33.2$ & $20.2 \pm 28.5^{\dagger}$ & $29.4 \pm 30.9$ & 0.0027 \\
\hline $\begin{array}{l}\text { Needed sleeping } \\
\text { medication to sleep }\end{array}$ & $16.9 \pm 29.7$ & $8.4 \pm 21.1^{\dagger}$ & $13.6 \pm 25.9$ & 0.0074 \\
\hline $\begin{array}{l}\text { Awakened by pain } \\
\text { at night }\end{array}$ & $45.8 \pm 31.3$ & $27.2 \pm 25.8^{\dagger}$ & $33.2 \pm 27.4^{\ddagger}$ & 0.0515 \\
\hline $\begin{array}{l}\text { Awakened by pain } \\
\text { in morning }\end{array}$ & $45.6 \pm 33.6$ & $24.7 \pm 24.7^{\dagger}$ & $33.5 \pm 27.8^{\ddagger}$ & 0.0020 \\
\hline Partner awakened & $28.7 \pm 29.6$ & $16.6 \pm 19.5^{\dagger}$ & $22.6 \pm 23.6$ & 0.0632 \\
\hline Hours of sleep & $6.0 \pm 1.6$ & $6.5 \pm 1.2^{\dagger}$ & $6.2 \pm 1.4^{\ddagger}$ & 0.0096 \\
\hline Quality of sleep & $41.8 \pm 25.7$ & $53.7 \pm 25.9^{\dagger}$ & $50.5 \pm 25.4$ & 0.2172 \\
\hline $\begin{array}{l}\text { Total pain and } \\
\text { sleep }\end{array}$ & $183.4 \pm 123.6$ & $104.7 \pm 98.0^{\dagger}$ & $141.0 \pm 108.2^{\ddagger}$ & 0.0008 \\
\hline
\end{tabular}

Results presented as mean $\pm S D$. ${ }^{*}$ Between treatments; ${ }^{\dagger}$ Change from baseline $P \leq 0.0030$; ${ }^{\ddagger}$ Change from baseline $P \leq 0.0023$

$\mathrm{P} \leq 0.0357)$, while such differences were only observed in two categories after placebo treatment (CFB range $8.1 \%$ to $10.9 \%$, $\mathrm{P} \leq 0.0111$ ). There was a significant $\mathrm{CFB}$ for the physical component scale following $\mathrm{CR}$ tramadol treatment, but this change was not significant after placebo treatment $(9.6 \%$ CFB, $\mathrm{P}=0.0001 ; 2.5 \% \mathrm{CFB}, \mathrm{P}=0.1973$ ). There was no significant change after either treatment on the mental component scale (Figure 4).

\section{Treatment effectiveness and preference}

Patients and investigators rated the effectiveness of CR tramadol as significantly higher than that of placebo (patients: $1.6 \pm 1.1$ versus $0.9 \pm 1.0, P=0.0001$; investigators: $1.5 \pm 1.1$ versus $0.9 \pm 1.0, \mathrm{P}=0.0010$ ). Patients receiving $\mathrm{CR}$ tramadol rated their treatment as moderately or highly effective in $55.8 \%$ of cases, while only $25 \%$ of patients receiving placebo provided the same rating of their treatment. Similarly, $52.0 \%$ of investigators rated CR tramadol as moderately or highly effective, while only 27.6\% gave the same rating to the placebo treatment.

Patients and investigators expressed significant preference for CR tramadol treatment. The per protocol population patients preferred the phase in which they received CR tramadol in $55.8 \%$ of cases; $20.8 \%$ of patients preferred the phase in which they received placebo and $23.4 \%$ had no preference $(\mathrm{P}=0.0005)$. Investigators preferred the phase in which patients received CR tramadol in $53.2 \%$ of patients, placebo in $18.2 \%$ of patients and had no preference in $27.3 \%$ of the cases $(\mathrm{P}=0.0004)$. These results were confirmed by the ITT analysis, in which $55.4 \%$ of patients preferred the phase in which they received CR tramadol, $19.3 \%$ preferred the phase in which they received placebo, and $21.7 \%$ had no preference $(\mathrm{P}=0.0001)$. Similarly, investigators preferred the $\mathrm{CR}$ tramadol phase in $51.8 \%$ of patients, the placebo phase in $16.9 \%$ of patients and had no preference in $26.5 \%$ of cases $(\mathrm{P}=0.0001)$.

\section{Adverse events}

Seventy-five patients (79.8\% of patients who received CR tramadol; $\mathrm{n}=94$ ) reported adverse events ( $\mathrm{AEs}$ ) during $\mathrm{CR}$

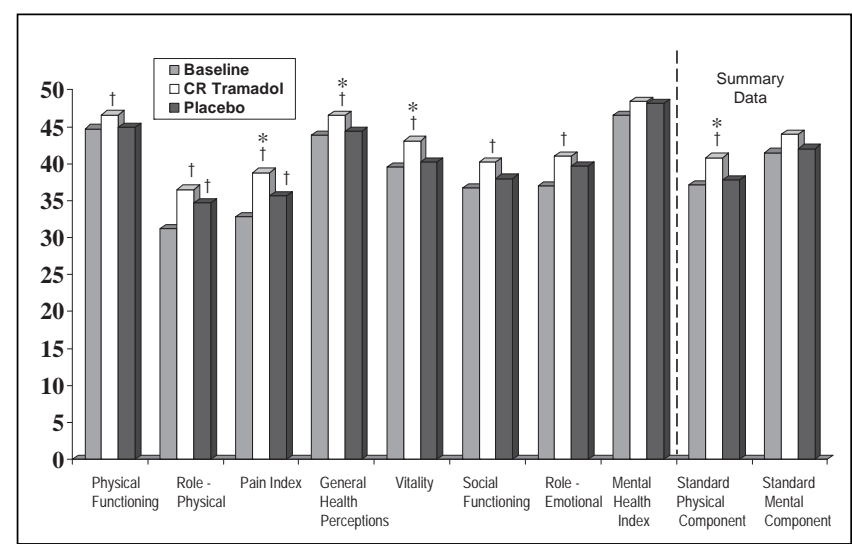

Figure 4) Short-form 36 Health Survey during the last week of treatment (per protocol population). Higher scores indicate a better health state. Data normalized to the Canadian population. *P $\leq 0.0262$ between treatments; ${ }^{\dagger} \mathrm{P} \leq 0.0357$ change from baseline. CR Controlledrelease

tramadol treatment. Fifty-eight patients $(65.9 \%$ of patients who received placebo; $\mathrm{n}=88$ ), reported AEs during placebo treatment. The difference in the overall frequency of AEs between treatment groups was not significant $(\mathrm{P}=0.0833)$. During the CR tramadol phase, 288 events were reported, with a mean maximum severity of $1.7(1=$ mild, $2=$ moderate; $3=$ severe). During the placebo phase, 166 events were reported, with a mean maximum severity of 1.5 . The most frequently reported AEs are listed in Table 3. There was significantly more nausea $(\mathrm{P}=0.0326)$, constipation $(\mathrm{P}=0.0011)$ and sweating $(\mathrm{P}=0.0253)$, and significantly less insomnia $(\mathrm{P}=0.0455)$ reported during $\mathrm{CR}$ tramadol treatment compared with placebo treatment.

Because the present study was a titration-to-effect study, the number of patients reporting AEs at a given dose was examined in a posthoc subanalysis. The majority of patients were receiving the $400 \mathrm{mg}$ dose $(61 \%)$, therefore the frequency of AEs was compared for low doses (150 mg, $200 \mathrm{mg}$ or $300 \mathrm{mg}$ ) and high doses $(400 \mathrm{mg}$ ) of CR tramadol. Patients on the high dose tended to have fewer AEs than patients on the lower doses. For example, nausea was reported by $60 \%$ of patients on the low doses, versus $29.6 \%$ of patients on the high dose. Similarly, somnolence was reported by $45.7 \%$ of patients on the low dose, compared with $31.5 \%$ of patients receiving the high dose. The incidence of constipation was similar on both low and high doses (25.7\% versus $24.1 \%$, respectively).

One serious AE occurred during the double-blind phase of the study. A patient with a history of supraventricular tachycardia experienced an atrial flutter while receiving $150 \mathrm{mg}$ of placebo. The patient was withdrawn from the study and was prescribed sotalol to control the arrhythmia.

\section{Open label extension}

Of 75 eligible patients, 53 (70.7\%) chose to receive CR tramadol in the open label phase. Twenty-four patients withdrew from the open label phase: nine due to AEs, four due to insufficient therapeutic effect, four due to resolution or remission of the treatment indication, one due to progression of the underlying disease, one due to a protocol violation, two were lost to follow-up, and three identified the reason for termination as 'other', which included an inability to attend clinic visits, 
TABLE 3

Incidence of most common adverse events (double-blind phase)*

\begin{tabular}{lccccc}
\hline & $\begin{array}{c}\text { Controlled- } \\
\text { release } \\
\text { tramadol, } \mathbf{n}(\%)\end{array}$ & $\begin{array}{c}\text { Mean } \\
\text { maximum } \\
\text { severity }\end{array}$ & $\begin{array}{c}\text { Placebo, } \\
\mathbf{n}(\%)\end{array}$ & $\begin{array}{c}\text { Mean } \\
\text { maximum } \\
\text { severity }\end{array}$ & $\mathbf{P}^{*}$ \\
\hline Nausea & $40(42.6)$ & 1.8 & $22(25.0)$ & 1.5 & 0.0326 \\
Somnolence & $35(37.2)$ & 1.6 & $19(21.6)$ & 1.5 & 0.0833 \\
Constipation & $22(23.4)$ & 1.3 & $5(5.7)$ & 1.6 & 0.0011 \\
Anorexia & $6(6.4)$ & 1.0 & $1(1.1)$ & 1.0 & 0.1025 \\
Vomiting & $6(6.4)$ & 1.8 & $2(2.3)$ & 2.0 & 0.3173 \\
Dizziness & $5(5.3)$ & 1.4 & $3(3.4)$ & 1.0 & 0.4142 \\
Sweating & $5(5.3)$ & 1.6 & $0(0.0)$ & 0 & 0.0253 \\
Asthenia & $3(3.2)$ & 1.7 & $3(3.4)$ & 1.3 & 0.6547 \\
Pruritus & $3(3.2)$ & 1.0 & $0(0.0)$ & 0 & 0.0833 \\
Headache & $2(2.1)$ & 1.5 & $6(6.8)$ & 1.3 & 0.1573 \\
Nervousness & $2(2.1)$ & 1.5 & $0(0.0)$ & 0 & 0.1573 \\
Insomnia & $0(0.0)$ & 0 & $4(4.5)$ & 1.8 & 0.0455 \\
Overall & $75(79.8)$ & 1.7 & $58(65.9)$ & 1.5 & 0.0833 \\
\hline
\end{tabular}

*Based on 94 patients who received controlled-release tramadol and 88 patients who received placebo

choice for elective surgery and noncompliance with study medication. Twenty-nine patients (54.7\%) completed the open label extension. The mean final dose of CR tramadol was $313.2 \pm 100.1 \mathrm{mg} /$ day, compared with $330.2 \pm 93.7 \mathrm{mg} /$ day during the last week of double-blind active treatment for these patients. The mean duration of exposure was $133.0 \pm 63.2$ days. When combined with the double-blind phase, the mean CR tramadol exposure was $161.2 \pm 63.0$ days.

For measures of pain intensity (VAS and ordinal scales, WOMAC pain subscale), functionality (WOMAC stiffness and physical function subscales, PDI) and sleep (Pain and Sleep Questionnaire), the significant changes achieved during the double-blind phase of the study were maintained throughout the duration of the open label phase $(\mathrm{P} \geq 0.1152)$. Mean values for primary end points and summary scales are presented in Table 4.

For the SF-36, the majority of categories showed no change from the values at the end of the double-blind phase $(\mathrm{P} \geq 0.1315)$. A significant decrease from baseline was observed in the physical functioning domain $(46.8 \%$ change from the end of the double-blind study, $\mathrm{P}=0.0001$ ). There was also a significant decrease in the overall physical component summary scale $(23.7 \%$ change from the end of the double-blind study, $\mathrm{P}=0.0001)$ and a significant increase in the mental component summary scale $(9.5 \%$ change from the end of the double-blind study, $\mathrm{P}=0.0011$ ) (Table 4).

At the end of the open label phase, the mean clinical benefit was $1.8 \pm 0.8$ on the ordinal pain intensity scale (where $1=$ a great deal of benefit, 2 = moderate benefit, $3=$ slight benefit, $4=$ no benefit). At the last open label visit, 23 patients $(44.2 \%)$ reported receiving moderate benefit, and 22 patients $(42.3 \%)$ reported receiving a great deal of benefit from CR tramadol.

There were 136 AEs reported by 40 patients during the open label extension, with a mean maximum severity of 1.8 . The most frequently reported adverse events were constipation (19 patients [35.9\%], mean maximum severity 1.4 ) and nausea (eight patients [15.1\%], mean maximum severity 1.5 ). Dyspepsia and somnolence were each reported by five patients (9.4\%, mean maximum severity 2.0 and 1.4 , respectively).
TABLE 4

Clinical benefit of controlled-release tramadol throughout long-term open label treatment

\begin{tabular}{|c|c|c|c|}
\hline Assessment & $\begin{array}{c}\text { End of } \\
\text { double-blind }\end{array}$ & $\begin{array}{l}\text { Open label } \\
\text { average }\end{array}$ & $\mathbf{P}^{*}$ \\
\hline VAS pain intensity & $35.4 \pm 22.7$ & $26.3 \pm 17.9$ & 0.7809 \\
\hline Ordinal pain intensity & $1.6 \pm 0.9$ & $1.8 \pm 0.7$ & 0.1376 \\
\hline WOMAC pain & $185.6 \pm 101.8$ & $177.2 \pm 81.6$ & 0.5735 \\
\hline $\begin{array}{l}\text { WOMAC physical } \\
\text { function }\end{array}$ & $609.1 \pm 364.3$ & $582.7 \pm 287.5$ & 0.5664 \\
\hline $\begin{array}{l}\text { Overall pain } \\
\text { and disability }\end{array}$ & $21.5 \pm 13.4$ & $21.6 \pm 10.1$ & 0.9660 \\
\hline $\begin{array}{l}\text { Overall pain } \\
\text { and sleep }\end{array}$ & $96.7 \pm 85.1$ & $89.2 \pm 78.8$ & 0.4555 \\
\hline $\begin{array}{l}\text { SF-36 standard } \\
\text { physical component }\end{array}$ & $41.1 \pm 8.4$ & $32.4 \pm 9.8$ & 0.0001 \\
\hline $\begin{array}{l}\text { SF-36 standard } \\
\text { mental component }\end{array}$ & $46.9 \pm 11.3$ & $51.1 \pm 10.2$ & 0.0011 \\
\hline
\end{tabular}

SF-36 Short-form 36 Health Survey; VAS Visual analogue scale; WOMAC Western Ontario and McMaster Universities osteoarthritis index

TABLE 5

Incidence of most common adverse events (open label phase)*

\begin{tabular}{lcccc}
\hline & $\begin{array}{c}\text { Mean } \\
\text { blind, n (\%) }\end{array}$ & $\begin{array}{c}\text { maximum } \\
\text { severity }\end{array}$ & $\begin{array}{c}\text { Open label, } \\
\mathbf{n ~ ( \% )}\end{array}$ & $\begin{array}{c}\text { Mean } \\
\text { maximum } \\
\text { severity }\end{array}$ \\
\hline Constipation & $17(32.1)$ & 1.3 & $19(35.9)$ & 1.4 \\
Nausea & $23(43.4)$ & 1.7 & $8(15.1)$ & 1.5 \\
Dyspepsia & $1(1.9)$ & 2.0 & $5(9.4)$ & 2.0 \\
Somnolence & $22(41.5)$ & 1.5 & $5(9.4)$ & 1.4 \\
Anorexia & $5(9.4)$ & 1.0 & $4(7.5)$ & 1.5 \\
Dizziness & $4(7.5)$ & 1.5 & $4(7.5)$ & 1.0 \\
Pain & $4(7.5)$ & 1.5 & $4(7.5)$ & 1.8 \\
Vasodilatation & $4(7.5)$ & 1.8 & $4(7.5)$ & 2.0 \\
Urinary tract & $0(0)$ & 0 & $4(7.5)$ & 1.5 \\
$\quad$ infection & & & & \\
Vomiting & $3(5.7)$ & 2.0 & $3(5.7)$ & 1.7 \\
Dry mouth & $9(17.0)$ & 1.0 & $3(5.7)$ & 1.0 \\
Insomnia & $0(0)$ & 0 & $3(5.7)$ & 1.7 \\
Hypertension & $1(1.9)$ & 1.0 & $3(5.7)$ & 1.3 \\
Accidental injury & $1(1.9)$ & 2.0 & $3(5.7)$ & 1.7 \\
\hline
\end{tabular}

*Based on 53 patients exposed to open label controlled-release tramadol treatment.

Anorexia, dizziness, pain, vasodilatation and urinary tract infection were each reported by four patients (7.5\%). Vomiting, dry mouth, insomnia, hypertension and accidental injury were each reported by three patients (5.7\%). There were two serious AEs during the open label phase, although both were scheduled orthopedic surgeries and were not related to the study medication. Table 5 presents the most common AEs reported during the open label phase, compared with their incidence during the double-blind phase.

\section{DISCUSSION}

The results of the present randomized, double-blind crossover study demonstrate that CR tramadol, at doses up to $400 \mathrm{mg} /$ day, was significantly more effective than placebo in the treatment of OA pain of the hip and/or knee. 
CR tramadol produced significantly lower scores than placebo in primary and secondary assessments of pain intensity (VAS and ordinal scales, pain intensity questionnaire, WOMAC pain subscale). Both treatment groups had access to acetaminophen as a rescue analgesic, which would be expected to reduce the magnitude of the difference in pain intensity between treatment phases, particularly because significantly more rescue analgesic was used in the placebo treatment phase. However, as also demonstrated in a number of previous studies, the use of an active rescue analgesic does not preclude convincing statistical separation of active and placebo treatments $(12,55,56,59,62)$. Both patients and investigators rated CR tramadol in a blinded manner as being significantly more effective than placebo. As well, significantly more patients and investigators preferred CR tramadol treatment (blinded) for the management of pain, indicating that the reductions in pain intensity produced by CR tramadol were clinically significant.

Significant improvements in physical functioning were evident from the WOMAC and the PDI. Pain is the most important determinant of disability in OA patients (63), and so the greater level of pain control provided by CR tramadol may also have allowed improved functionality and reduced disability. Patients reported significantly better sleep with CR tramadol. Sleep disturbance is a prevalent complaint among patients with chronic pain, and thus the improvement of sleep quality is an important goal in pain management (64). Finally, overall quality of life was significantly better with CR tramadol than with placebo treatment, as reflected in the SF-36. The efficacy observed in all of the secondary outcome measures was also reflected in both the patient and investigator preference for CR tramadol.

A recent meta-analysis based on a Cochrane Review of tramadol in OA found gold standard evidence that tramadol is more effective than placebo at reducing pain intensity, producing relief of symptoms and improving function (65). The review noted that the expected decrease in pain intensity would be no more than 12.5 on a scale of 1 to 100 . The present study reported a decrease from baseline of $13.4 \mathrm{~mm}$, suggesting a strong response to this CR formulation. Similarly, the functional improvements observed in the present study were more robust (WOMAC pain 34.5\%, physical function $29.4 \%$ ) than the $8.5 \%$ cited in the meta-analysis. Our results therefore provide supportive evidence for the benefit of tramadol in OA pain, and demonstrate the efficacy of this CR formulation in particular.

The results of the present study also demonstrate the appropriateness of the titration-to-effect approach for CR tramadol in minimizing discontinuation of treatment due to AEs. The availability of a wide range of doses of this preparation facilitates appropriate titration to an optimal dose that balances analgesia and side effects. Other once-per-day formulations of tramadol are off-label at doses above $300 \mathrm{mg} /$ day, whereas this CR tramadol can be dosed to a maximum of $400 \mathrm{mg} /$ day. The overall rate of withdrawal in the double-blind phase was $25 \%$, but the withdrawal rate due to adverse events in the CR tramadol treatment group was only $12 \%$. Two previously published studies on IR tramadol, using doses up to $200 \mathrm{mg} /$ day titrated over one to 10 days, indicated rates of discontinuation due to intolerable side effects as high as $31 \%$ to $54 \%$, which was attributed to the rapid titration of the product $(66,67)$. Slower titration rates of IR tramadol over 10 to 16 days resulted in significantly lower incidence (15\% to 30\%) of withdrawals due to adverse events $(66,67)$. In a previous crossover study, comparing this CR formulation with IR tramadol in doses up to $400 \mathrm{mg} /$ day using titration every two weeks, the withdrawal rate due to adverse events was similarly low at $19.7 \%$ (50). Another study with the same titration (every two weeks) and dosing up to $400 \mathrm{mg} /$ day, comparing CR tramadol and sustained-release diclofenac, resulted in withdrawal rates due to adverse events of only $16 \%$ (68). The present study, as well as the two previous studies using CR tramadol titrated every one to two weeks, indicated that tolerability of CR tramadol was as good as, if not better than, that of IR tramadol titrated every 10 to 16 days. In the open label phase, the withdrawal rate due to adverse events was $17 \%$. Both double-blind and open label withdrawal rates were in concordance with previous studies $(50,66-68)$, and confirmed that this formulation is well-tolerated for long-term therapy at doses up to $400 \mathrm{mg} /$ day.

In the present study, there was no significant difference in the overall incidence of AEs between the treatment groups. The most common AEs were typical opioid-related side effects. Consistent with CR tramadol's pharmacological profile, there was significantly more nausea, constipation and sweating in patients taking CR tramadol. However, most events were not classified as severe, and there were no serious AEs in patients receiving CR tramadol. Furthermore, there was no indication of an increase in AEs at higher doses. In the open label phase, constipation and nausea were again the most common adverse events. However, the percentage of patients reporting nausea during the open label phase $(15.1 \%)$ was approximately onethird of the percentage that reported it during the double-blind phase $(43.4 \%)$. Similarly, while $41.5 \%$ of patients reported somnolence during the double-blind phase, only $9.4 \%$ of patients reported it during the open label phase. It has been previously demonstrated that some AEs that occur at the onset of therapy diminish with continued treatment (69). There were no serious AEs during long-term treatment that were considered related to CR tramadol.

The results of the long-term open label extension of the present study demonstrated that CR tramadol is effective for the long-term management of OA pain. Reductions in pain intensity, improvements in sleep and functionality, and the majority of quality of life measures reported during the randomized phase of the study were sustained throughout the open label phase. The mean final dose of CR tramadol during the open label phase was comparable with the mean dose in the double-blind phase, suggesting that pain control was maintained without the development of analgesic tolerance. There was some decline in certain quality of life measures over the course of the open label phase (physical function and physical component summary scale of the SF-36). OA is a progressive degenerative disease, and it is not unexpected that patients may deteriorate over a six-month period. Further, since CR tramadol is indicated to treat the secondary symptom of pain and not the disease process, a decline in physical function could be anticipated. Despite these changes, the maintenance of pain control, coupled with the patient perception of clinical benefit from CR tramadol (86.5\% of patients reported at least moderate benefit) confirmed the efficacy and tolerability of treatment over the long term.

The present study demonstrated significant differences between CR tramadol and placebo at the end of the treatment 
period, not only with respect to pain intensity, but also for functional improvement and quality of life. In addition, these improvements were sustained over the course of a six-month open label extension. While there were more opioid-related side effects with CR tramadol in the double-blind phase, they were of mild to moderate severity. There was no difference in the overall incidence of AEs between the groups, and reports of AEs tended to decrease with increasing duration of treatment. Furthermore, the rate of withdrawal from the study due to AEs was low, despite a maximum dose of $400 \mathrm{mg} /$ day, a dose that is off-label with other once-daily tramadol preparations in North America. CR tramadol is therefore an efficacious and well-tolerated medication for the treatment of OA pain.

ACKNOWLEDGEMENT: The authors wish to thank the late Dr John T Sibley, MD (Royal University Hospital, Saskatoon, Saskatchewan) for his contributions and recruitment of patients for this study.

SUPPORT: Supported by a research grant from Purdue Pharma, Canada.

\section{REFERENCES}

1. Health Canada. Arthritis in Canada. An ongoing challenge. <http://www.phac-aspc.gc.ca/publicat/ac/pdf/ac_e.pdf> (Version current at March 18, 2008).

2. Breedveld FC. Osteoarthritis - the impact of a serious disease. Rheumatology (Oxford) 2004;43(Suppl 1):i4-8.

3. Liang MH, Fortin P. Management of osteoarthritis of the hip and knee. N Engl J Med 1991;325:125-7.

4. Gupta S, Hawker GA, Laporte A, Croxford R, Coyte PC. The economic burden of disabling hip and knee osteoarthritis (OA) from the perspective of individuals living with this condition. Rheumatology (Oxford) 2005;44:1531-7.

5. World Health Organization. Cancer Pain Relief, With a guide to opioid availability, 2nd ed. Geneva: World Health Organization, 1996.

6. Levy MH. Pharmacologic treatment of cancer pain. N Engl J Med 1996;335:1124-32.

7. Ofman JJ, MacLean CH, Straus WL, et al. A meta-analysis of severe upper gastrointestinal complications of nonsteroidal antiinflammatory drugs. J Rheumatol 2002;29:804-12.

8. McGettigan P, Henry D. Cardiovascular risk and inhibition of cyclo-oxygenase: A systematic review of the observational studies of selective and nonselective inhibitors of cyclo-oxygenase 2 . JAMA 2006;296:1633-44.

9. Safety information regarding selective COX-2 inhibitor NSAIDs: Vioxx (rofecoxib), Celebrex (celecoxib), Bextra (valdecoxib), Mobicox (meloxicam) and generic forms of meloxicam. $<$ http://www.hc-sc.gc.ca/ahc-asc/media/advisoriesavis/_2004/2004_69_e.html> (Version current at March 18, 2008).

10. Health Canada has asked Pfizer to suspend sales of its drug Bextra and informs Canadians of new restrictions on the use of Celebrex. $<$ http://www.hc-sc.gc.ca/ahc-asc/media/advisoriesavis/_2005/2005_17_e.html> (Version current at March 18, 2008).

11. Antman EM, Bennett JS, Daugherty A, Furberg C, Roberts $H$, Taubert KA; for the American Heart Association. Use of nonsteroidal anti-inflammatory drugs: An update for clinicians: A scientific statement from the American Heart Association. Circulation 2007;115:1634-42.

12. Arkinstall W, Sandler A, Goughnour B, Babul N, Harsanyi Z, Darke AC. Efficacy of controlled-release codeine in chronic nonmalignant pain: A randomized, placebo-controlled clinical trial. Pain 1995;62:169-78.

13. Darke AC, Stewart JH. Efficacy and abuse potential of opioid analgesics and the treatment of chronic noncancer pain. Pain Res Manage 1999;4:104-9.

14. Peloso PM, Bellamy N, Bensen W, et al. Double blind randomized placebo control trial of controlled release codeine in the treatment of osteoarthritis of the hip or knee. J Rheumatol 2000;27:764-71.
15. A Russell, CP Watson, AJ Clark, et al. Evaluation of dosing guidelines for use of controlled-release codeine in chronic noncancer pain. Pain Res Manage 2003;8:143-8.

16. Raffa RB, Friderichs E, Reimann W, Shank RP, Codd EE, Vaught JL. Opioid and nonopioid components independently contribute to the mechanism of action of tramadol, an 'atypical' opioid analgesic. J Pharm Exp Ther 1992;260:275-85.

17. Richter W, Barth H, Flohé L, Giertz H. Clinical investigation on the development of dependence during oral therapy with tramadol. Arzneimittelforschung 1985;35:1742-4.

18. Lee CR, McTavish D, Sorkin EM. Tramadol. A preliminary review of its pharmacodynamic and pharmacokinetic properties, and therapeutic potential in acute and chronic pain states. Drugs 1993;46:313-40.

19. Cicero TJ, Adams EH, Geller A, et al. A postmarketing surveillance program to monitor Ultram (tramadol hydrochloride) abuse in the United States. Drug Alcohol Depend 1999;57:7-22.

20. Knisely JS, Campbell ED, Dawson KS, Schnoll SH. Tramadol postmarketing surveillance in health care professionals. Drug Alcohol Depend 2002;68:15-22.

21. WHO Expert Committee on Drug Dependence. Thirty-fourth report. <http://whqlibdoc.who.int/trs/WHO_TRS_942_eng.pdf> (Version current March 18, 2008).

22. Houmes RJ, Voets MA, Verkaaik A, Erdmann W, Lachmann B. Efficacy and safety of tramadol versus morphine for moderate and severe postoperative pain with special regard to respiratory depression. Anesth Analg 1992;74:510-4

23. Chrubasik J, Buzina M, Schulte-Mönting J, Atanassoff P, Alon E. Intravenous tramadol for post-operative pain - comparison of intermittent dose regimens with and without maintenance infusion. Eur J Anaesthesiol 1992;9:23-8.

24. Wilder-Smith $\mathrm{CH}$, Bettiga A. The analgesic tramadol has minimal effect on gastrointestinal motor function. Br J Clin Pharmacol 1997;43:71-5.

25. Wilder-Smith CH, Hill L, Spargo K, Kalla A. Treatment of severe pain from osteoarthritis with slow-release tramadol or dihydrocodeine in combination with NSAIDs: A randomised study comparing analgesia, antinociception and gastrointestinal effects. Pain 2001;91:23-31.

26. Moore RA, McQuay HJ. Single-patient data meta-analysis of 3453 postoperative patients: Oral tramadol versus placebo, codeine and combination analgesics. Pain 1997;69:287-94.

27. Schnitzer TJ, Gray WL, Paster RZ, Kamin M. Efficacy of tramadol in treatment of chronic low back pain. J Rheumatol 2000;27:772-8.

28. Wilder-Smith CH, Schimke J, Osterwalder B, Senn HJ. Oral tramadol, a $\mu$-opioid agonist and monoamine reuptake blocker, and morphine for strong cancer-related pain. Ann Oncol 1994;5:141-6.

29. Grond S, Radbruch L, Meuser T, Loick G, Sabatowski R, Lehmann KA. High-dose tramadol in comparison to low-dose morphine for cancer pain relief. J Pain Symptom Manage 1999; 18:174-9.

30. Harati Y, Gooch C, Swenson M, et al. Double-blind randomized trial of tramadol for the treatment of the pain of diabetic neuropathy. Neurology 1998;50:1842-6.

31. Harati Y, Gooch C, Swenson M, et al. Maintenance of the longterm effectiveness of tramadol in treatment of the pain of diabetic neuropathy. J Diabetes Complications 2000;14:65-70.

32. Sindrup SH, Andersen G, Madsen C, Smith T, Brøsen K, Jensen TS. Tramadol relieves pain and allodynia in polyneuropathy: A randomised, double-blind, controlled trial. Pain 1999;83:85-90.

33. Russell IJ, Kamin M, Sager DS, et al. Efficacy of tramadol in treatment of pain in fibromyalgia. Arthritis Rheum 1997;40(Suppl):S521.

34. Dalgin P. Comparison of tramadol and ibuprofen for the chronic pain of osteoarthritis. Arthritis Rheum 1997;40(Suppl):S86.

35. Pavelka K. Treatment of pain in osteoarthritis. Eur J Pain 2000;4(Suppl A):23-30.

36. Adler L, McDonald C, O'Brien C, Wilson M. A comparison of once-daily tramadol with normal release tramadol in the treatment of pain in osteoarthritis. J Rheumatol 2002;29:2196-9.

37. Bodalia B, McDonald CJ, Smith KJ, O'Brien C, Cousens L. A comparison of the pharmacokinetics, clinical efficacy, and tolerability of once-daily tramadol tablets with normal release tramadol capsules. J Pain Symptom Manage 2003;25:142-9.

38. Fleischmann RM, Caldwell JR, Roth SH, Tesser JRP, Olson W, Kamin M. Tramadol for the treatment of joint pain associated with 
osteoarthritis: A randomized, double-blind, placebo-controlled trial. Curr Ther Res 2001;62:113-28.

39. Bianchi M, Broggini M, Balzarini P, et al. Effects of tramadol on synovial fluid concentrations of substance $P$ and interleukin- 6 in patients with knee osteoarthritis: Comparison with paracetamol. Int Immunopharmacol 2003;3:1901-8.

40. Babul N, Noveck R, Chipman H, Roth SH, Gana T, Albert K. Efficacy and safety of extended-release, once-daily tramadol in chronic pain: A randomized 12-week clinical trial in osteoarthritis of the knee. J Pain Symptom Manage 2004;28:59-71.

41. Malonne H, Coffiner M, Sonet B, Sereno A, Vanderbist F. Efficacy and tolerability of sustained-release tramadol in the treatment of symptomatic osteoarthritis of the hip or knee: A multicenter, randomized, double-blind, placebo-controlled study. Clin Ther 2004:26:1774-82.

42. Simon L, Lipman A, Jacox A. Guideline for the Management of Pain in Osteoarthritis, Rheumatoid Arthritis and Juvenile Chronic Arthritis, 2nd ed. Glenview: American Pain Society, 2002.

43. Mullican WS, Lacy JR; for the TRAMAP-ANAG-006 Study Group. Tramadol/acetaminophen combination tablets and codeine/acetaminophen combination capsules for the management of chronic pain: A comparative trial. Clin Ther 2001;23:1429-45.

44. Bennett RM, Kamin M, Karim R, Rosenthal N. Tramadol and acetaminophen combination tablets in the treatment of fibromyalgia pain: A double-blind, randomized, placebo-controlled study. Am J Med 2003;114:537-45.

45. Ruoff GE, Rosenthal N, Jordan D, Karim R, Kamin M; for the Protocol CAPSS-112 Study Group. Tramadol/acetaminophen combination tablets for the treatment of chronic lower back pain: A multicenter, randomized, double-blind, placebo-controlled outpatient study. Clin Ther 2003;25:1123-41.

46. Rosenthal NR, Silverfield JC, Wu SC, Jordan D, Kamin M; for the CAPSS-105 Study Group. Tramadol/acetaminophen combination tablets for the treatment of pain associated with osteoarthritis flare in an elderly patient population. J Am Geriatr Soc 2004;52:374-80.

47. Emkey R, Rosenthal N, Wu SC, Jordan D, Kamin M; for the CAPSS-114 Study Group. Efficacy and safety of tramadol/acetaminophen tablets (Ultracet) as add-on therapy for osteoarthritis pain in subjects receiving a COX-2 nonsteroidal antiinflammatory drug: A multicenter, randomized, double-blind, placebo-controlled trial. J Rheumatol 2004;31:150-6.

48. Silverfield JC, Kamin M, Wu SC, Rosenthal N; for the CAPSS-105 Study Group. Tramadol/acetaminophen combination tablets for the treatment of osteoarthritis flare pain: A multicenter, outpatient, randomized, double-blind, placebo-controlled, parallel-group, addon study. Clin Ther 2002;24:282-97.

49. Napp Laboratories Limited. An open, single dose, three-part, randomized crossover study to investigate the effects of food on the pharmacokinetics of tramadol from tramadol CR compressed multiparticulate tablet $200 \mathrm{mg}$ (Tramadol OD, NRC) referenced to tramadol hydrochloride oral solution $100 \mathrm{mg}$. Final Study Report. Cambridge (UK): Medical Affairs Department, Napp Laboratories Limited, UK: January 1997. Report TRAM.CLIN0006. Data on file.

50. Beaulieu AD, Peloso P, Bensen W, et al. A randomized, doubleblind, 8-week crossover study of once-daily controlled-release tramadol versus immediate-release tramadol taken as needed for chronic noncancer pain. Clin Ther 2007;29:49-60.
51. Symposium on Population Studies in Relation to Chronic Rheumatic Diseases, Rome, 1961. The Epidemiology of Chronic Rheumatism, Volume 2: Atlas of Standard Radiographs of Arthritis. Philadelphia: FA Davis, 1963.

52. Bellamy N. Pain assessment in osteoarthritis: Experience with the WOMAC osteoarthritis index. Semin Arthritis Rheum 1989;18:14-7.

53. Pollard CA. Preliminary validity study for the pain disability index. Percept Mot Skills 1984;59:974.

54. Tait RC, Chibnall JT, Krause S. The Pain Disability Index: Psychometric properties. Pain 1990;40:171-82.

55. Watson CP, Babul N. Efficacy of oxycodone in neuropathic pain: A randomized trial in postherpetic neuralgia. Neurology 1998;50:1837-41

56. Watson CP, Moulin D, Watt-Watson J, Gordon A, Eisenhoffer J. Controlled-release oxycodone relieves neuropathic pain: A randomized controlled trial in painful diabetic neuropathy. Pain 2003; $105: 71-8$

57. Hagen NA, Thirlwell M, Eisenhoffer J, Quigley P, Harsanyi Z Darke A. Efficacy, safety, and steady-state pharmacokinetics of once-a-day controlled-release morphine (MS Contin XL) in cancer pain. J Pain Symptom Manage 2005;29:80-90.

58. Bronfort G, Bouter LM. Responsiveness of general health status in chronic low back pain: A comparison of the COOP charts and the SF-36. Pain 1999; 83:201-9.

59. Sibley J, Kelly A, Rashiq S, et al. Controlled release oxycodone and acetaminophen plus codeine in chronic low back pain. In: Abstracts of the 10th World Congress on Pain. San Diego: International Association for the Study of Pain, 2002:429.

60. Jones B, Kenward MG. Design and Analysis of Cross-Over Trials, 2nd ed. Boca Raton: Chapman and Hall/CRC, 2003.

61. National Technical Information Service. Coding symbols for a thesaurus of adverse reaction terms (COSTART), 4th edn. Springfield: National Technical Information Service, 1992.

62. Rashiq S, Moulin DF, Sibley J, et al. Randomized placebocontrolled trial of buprenorphine transdermal system in patients with chronic low back pain. Pain Res Manage 2005;10:103. (Abst)

63. Woolf AD, Pfleger B. Burden of major musculoskeletal conditions. Bull World Health Organ 2003;81:646-56.

64. Morin CM, Gibson D, Wade J. Self-reported sleep and mood disturbance in chronic pain patients. Clin J Pain 1998;14:311-4.

65. Cepeda MS, Camargo F, Zea C, Valencia L. Tramadol for osteoarthritis: A systematic review and meta-analysis. J Rheumatol 2007;34:543-55.

66. Ruoff GE. Slowing the initial titration rate of tramadol improves tolerability. Pharmacotherapy 1999;19:88-93.

67. Petrone D, Kamin M, Olson W. Slowing the titration rate of tramadol $\mathrm{HCl}$ reduces the incidence of discontinuation due to nausea and/or vomiting: A double-blind randomized trial. J Clin Pharm Ther 1999;24:115-23.

68. Beaulieu AD, Peloso PM, Haraoui B, et al. Once-daily controlledrelease tramadol and sustained-release diclofenac relieve chronic pain due to osteoarthritis: a randomized controlled trial. Pain Res Manage 2008;13:103-10.

69. Sorge J, Stadler TH. Comparison of the analgesic efficacy and tolerability of tramadol $100 \mathrm{mg}$ sustained-release tablets and tramadol $50 \mathrm{mg}$ capsules for the treatment of chronic low back pain. Clin Drug Investig 1997;14:157-64. 


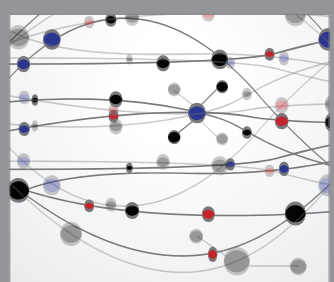

The Scientific World Journal
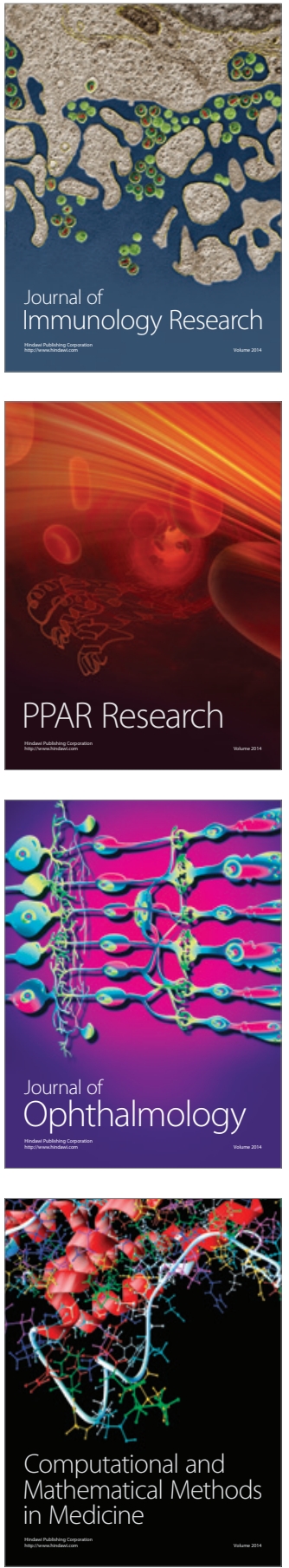

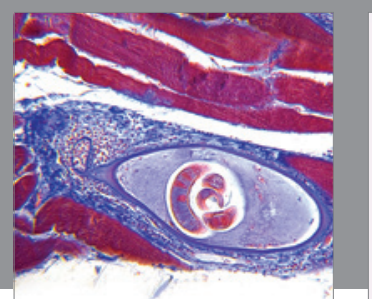

Gastroenterology Research and Practice

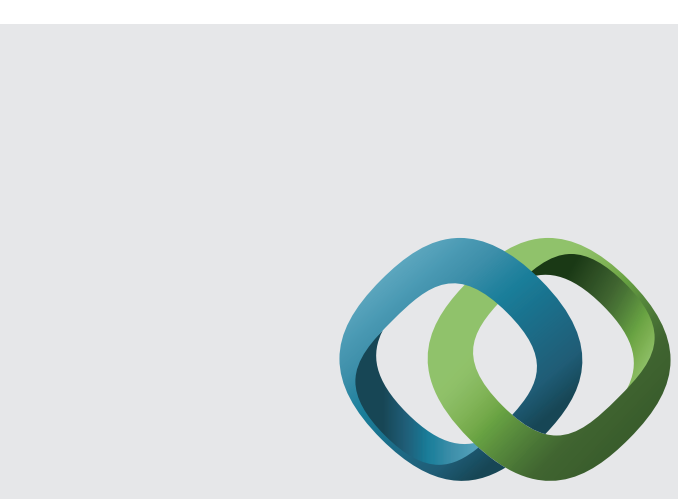

\section{Hindawi}

Submit your manuscripts at

http://www.hindawi.com
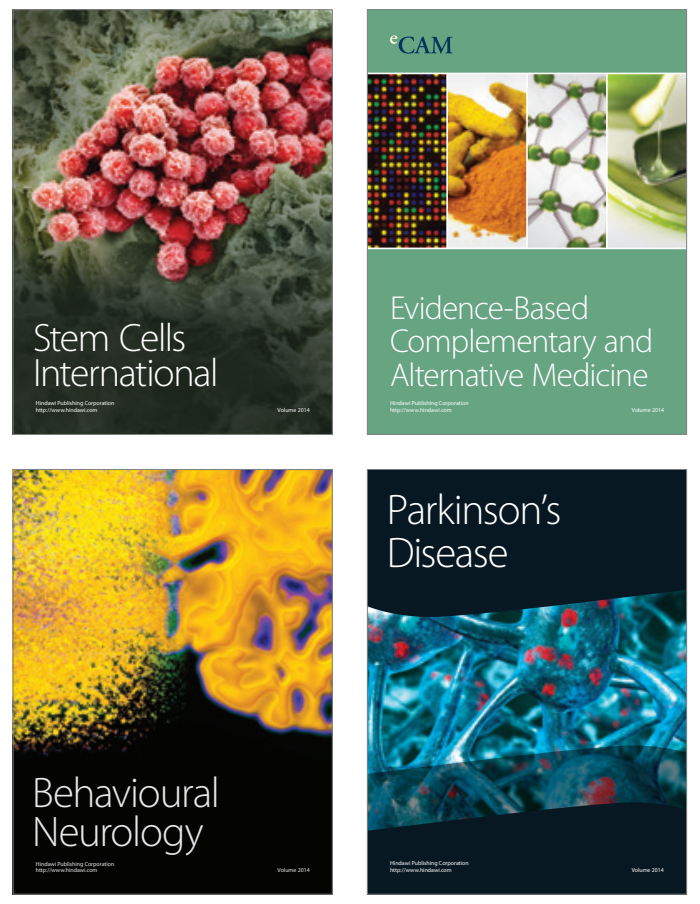
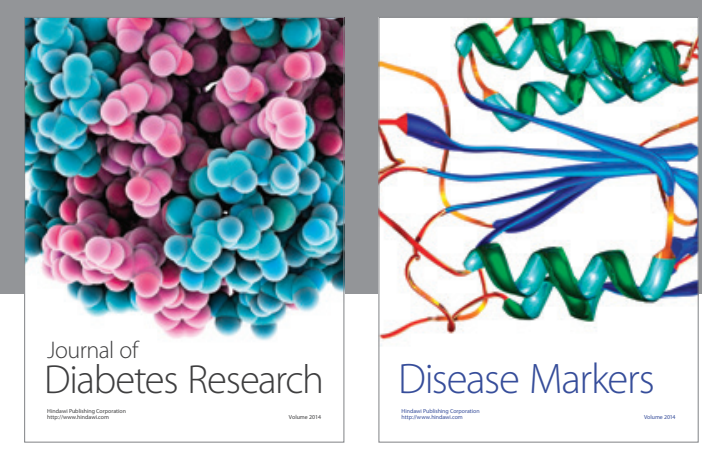

Disease Markers
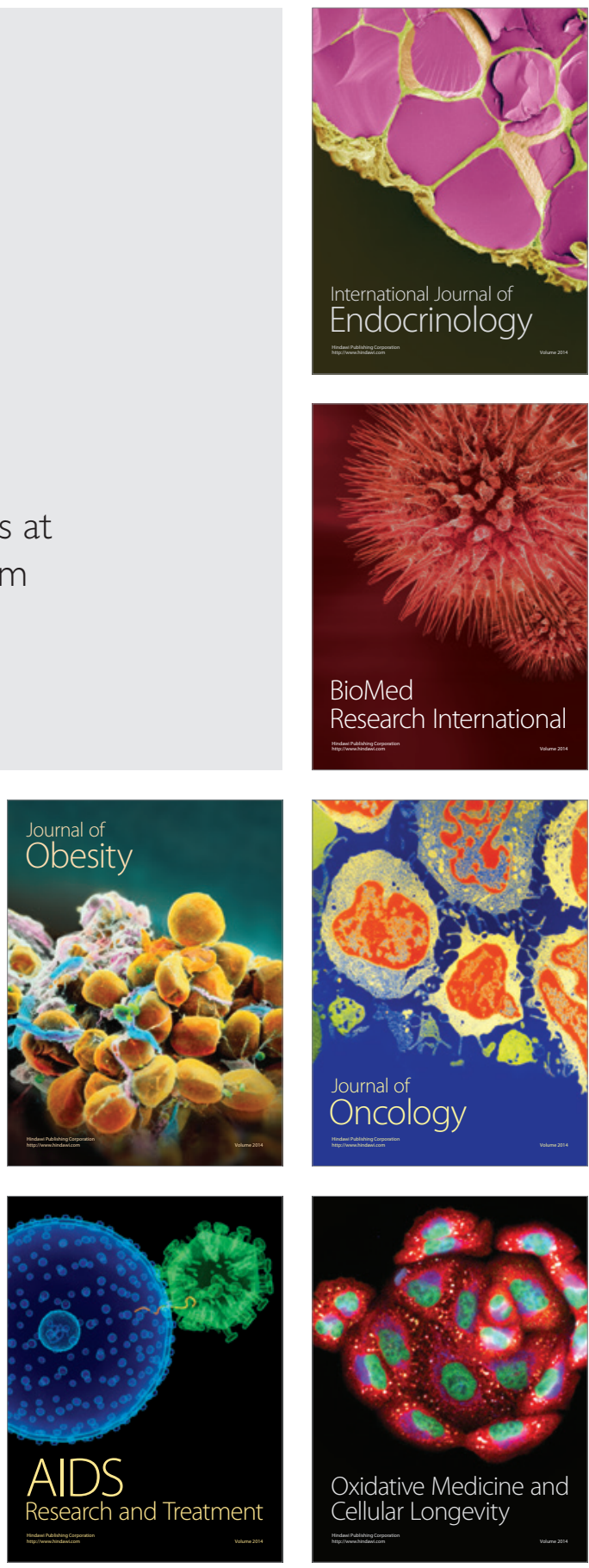